\title{
New complexes based on benzimidazole and imidazole derivatives
}

$\underline{\text { Sofiane Bouacida }}^{1}$, Feriel Aouatef Sahki ${ }^{2}$, Abdelmalek Bouraiou ${ }^{2}$

${ }^{1}$ Oum El Bouaghi University, Oum El Bouaghi, Algeria, 2 Unité de Recherche de Chimie de l'Environnement et Moléculaire Structurale, Université des frères Mentouri., Constantine, Algeria

E-mail: bouacida_sofiane@yahoo.fr

Nitrogen and sulfur-based ligands are extensively studied as complexes with many metal ions. They have attracted great attention because of their potential applications in various fields of human interest such as antitumor, antiviral, antifungal, antibacterial and antioxidant drugs. In addition to the biological importance, diverse catalytic and magnetic properties of such compounds have been explored.

Following our previous works related to the use of benzazole thioether as ligand for new coordination complexes, a new Mn, $\mathrm{Co}, \mathrm{Zn}, \mathrm{Hg}$ and $\mathrm{Cd}$ complexes containing a polydentate ligand, by combination of imidazole and benzimidazole fragments have been synthesized.

A ligand, 2-(((1-methyl-1H-imidazol-2-yl)methylthio)methyl)-1H-benzo[d]imidazole and its five complex of Zn(II), Cd(II), $\mathrm{Co}(\mathrm{II}), \mathrm{Hg}$ (II) and $\mathrm{Mn}$ (II) have been prepared. The molecular structure of ligand and its complex are determined by single crystal X-ray diffraction technique. We report here the synthesis, crystallographic study, hydrogen bond interactions and theoretical investigation of five new coordination complexes based on benzimidazole and imidazole derivatives.

In order to provide a better understanding of the bonding and the electronic structure of the ligand and their neutral complexes, we have carried out DFT calculations. The optimized structures reproduce those observed experimentally, while the reduced ones undergo remarkable geometrical parameters.<smiles>SCc1nc2ccccc2[nH]1</smiles><smiles>Cn1ccnc1CCl</smiles><smiles>CO[14C](=O)O[Na]</smiles><smiles>Cn1ccnc1CSCc1nc2ccccc2[nH]1</smiles>

Keywords: Imidazole and Benzimidazole, Single crystal, DFT calculations 